will ultimately dominate virgin substrata initially colonized by Fucus vesiculosus. The senior author has long considered it a probability that $A$. nodosum might exude something which inhibits the development of competitive algæ, and to test this, zoospores of Laminaria Cloustoni were grown in natural sea water with a piece of living, mature $A$. nodosum. The water of this particular tank was noticeably clearer than any of the others, and inspection after 28 days showed the zoospores to be completely decolorized. (Of the marine aquaria maintained in the laboratory, the water of one containing $A$. nodosum sporelings always remains the clearest.)

From this, three points emerge : (1) A. nodosum produces an antibiotic ; (2) the effects of this antibiotic in decolorizing the chlorophyll serves a useful means for more easily studying the nuclei of $L$. Cloustoni, which unfortunately are structurally minute; and (3) is the zonation of the littoral Fucaceæ due to 'chemical claws'?

The nuclei of the normal spores, the spores grown with uranium nitrate and $A$. nodosum appear visually similar. They comprise two small stainable masses within a sac of clear material.

Full details will be published elsewhere with full bibliography.

\author{
F. T. WALKER \\ Margaret McL. Smith \\ Institute of Seaweed Research, \\ Musselburgh, Midlothian. \\ March 15. \\ "Fritsch, F. E., "The Structure and Reproduction of the Algæ", \\ $2(1945)$. \\ ${ }^{2}$ Harris, R., Ann. Bot., 46, No. 184 (1932), \\ 3 Bold, H. C., Bot. Rev., 8, (2), 69 (1942). \\ - Pearsall, W. M., Nature, 122, 729 (1928). \\ Walker, F. T., Proc. Linn. Soc., 169, Part 2 (1947).
}

\section{Growth of Phytophthora infestans (Mont.) de Bary on Artificial Media}

IT appears from the literature on Phytophthora infestans that many workers have had difficulty in growing this fungus and in obtaining a supply of sporangia. The fungus grows and fructifies well on potato leaves and tuber slices, but such cultures require frequent renewal. Recently Snieszko et al. ${ }^{1}$ in the United States described various media which supported growth, particularly a cereal grains-pea. nut hull mixture upon which the fungus spored freely. Peanut hulls are not readily available in Great Britain.

In this laboratory, media for the culturing of $P$. infestans have been made from germinated oats, wheat, maize and pea and from dried leaves of potato and tomato. At its best the dried potato leaf medium was much superior to all other materials tried. Sporulation was sometimes so abundant that cultures had a powdery rather than a downy appearance. Unfortunately, as with oat, wheat, maize and tomato, this medium was unreliable, often giving poor growth and sporulation. A reliable medium made from pea. flour has now been evolved. It is felt worth while to publish the information, although the method is by no means perfected.

This medium contains $2 \cdot 5$ per cent pea-flour, $2 \cdot 5$ per cent sucrose, 1 per cent agar and distilled water. The sucrose, agar and half the water are sterilized at $15 \mathrm{lb}$. pressure for $15 \mathrm{~min}$., and to this is then added the pea-flour in the rest of the water heated to $40^{\circ} \mathrm{C}$. After rapid and thorough mixing, the medium is tubed and plugged. The tubes are left at laboratory temperature for $18-24 \mathrm{hr}$., sterilized at $10 \mathrm{lb}$. pressure for $6 \mathrm{~min}$. and sloped.

The pea-flour is made from garden peas grown in sand under glass. When the plants are $2-3$ in. high, their leaves and stems are chopped up and dried on glass sheets in an electric oven at $55-60^{\circ} \mathrm{C}$. The time taken for drying varies from two to three hours. The dried material is ground with a hand-mill and stored in screw-capped bottles in the dark.

This pea-flour medium has been in use for more than a year, and in no instance has the fungus failed to grow or sporulate on any batch of it. Some isolates of $P$. infestans, however, grow more rapidly and spore more freely than others. In test-tubes $(6 \mathrm{in}$. by $\frac{5}{8}$ in., $5 \mathrm{ml}$. medium) at $18^{\circ} \mathrm{C}$. the fungus usually covers the agar in a week and sporing begins in two to three weeks. Sporulation is greater if the cultures are stored in closed jars. The danger of mould contamination arising from these damp conditions can be avoided by exposing the cultures once weekly to room humidity for a few hours and replacing them in clean, dry jars. If the fungus is grown in boiling tubes ( 7 in. by 1 in., 15 ml. medium), good sporulation will take place even if the cultures are not kept enclosed. It is advisable, however, to keep them in jars until the fungus is well established.

Some isolates of the fungus survive longer in culture than do others. Test-tube cultures kept at $18^{\circ} \mathrm{C}$. require subculturing every four to five weoks; at $10^{\circ} \mathrm{C}$. every ten to twelve weeks. In boiling tubes, some cultures have remained alive for as long as seventeen weeks, whereas others have lasted only ten to twelve weeks.

Spores produced by $P$. infestans on this pea-flour medium have infected potato seedlings, tubers and adult leaves. The effect of continuous cultivation on the pathogenicity of the fungus is under investigation. SYDNEY DICKINSON

\section{School of Agriculture,} Cambridge.

\author{
Commonwealth Potato Station, \\ Cambridge. \\ March 22. \\ Margaret A. Keay
} 'Snieszko, S. F., Carpenter, J. B., Lowe, E. P., and Jakob, J. G.,
Phytopath., $\mathbf{3 7}, 635$ (1947).

\section{Hysteresis in the Swelling of Gels}

HYGROSCOPIC natural fibres generally show sorption hysteresis, such that the vapour pressure at any given moisture content is higher on adsorption than on desorption, whereas no hysteresis is found in true solutions.

In 1942 I suggested ${ }^{1}$ that sorption hysteresis in gels could be explained in terms of their plastic properties. This deduction is based on the fact that the vapour pressure of a gel is determined by the hydrostatic stress acting on it as well as by the moisture content. It can be shown ${ }^{2}$ that, if either anatomical or molecular restraints oppose the free swelling and introduce plastic flow under shear stresses, the hydrostatic component $p$ of the stress system, and therefore also the vapour pressure $h$, will be higher on adsorption than on desorption at any given moisture content $m$.

If, between adsorption and desorption, the difference in hydrostatic pressure is $\Delta p$, this must produce a change in volume of the gel: $\Delta V=-V \Delta p / k$, where $k$ is the bulk modulus; while the value of 